\title{
Formulation and cytotoxicity evaluation of new self-emulsifying multiple W/O/W nanoemulsions
}

This article was published in the following Dove Press journal:

International Journal of Nanomedicine

5 February 2013

Number of times this article has been viewed

\author{
Estelle Sigward' \\ Nathalie Mignet ${ }^{\prime}$ \\ Patrice Rat $^{2}$ \\ Mélody Dutot ${ }^{2}$ \\ Saleh Muhamed' \\ Jean-Michel Guigner ${ }^{3}$ \\ Daniel Scherman' \\ Denis Brossard' \\ Sylvie Crauste-Manciet' \\ 'Chemical, Genetic and Imaging \\ Pharmacology Laboratory; INSERM \\ UI022, CNRS UMR8I5I, Chimie \\ ParisTech, Faculty of Pharmacy, Paris \\ Descartes University, Sorbone Paris \\ Cité, Paris, France; ${ }^{2}$ Chemistry- \\ Cellular and Analytical Toxicology \\ Laboratory (C-TAC), Faculty of \\ Pharmacy, Paris Descartes University, \\ Sorbone Paris Cité, Paris, France; \\ ${ }^{3}$ Institut de Minéralogie et de \\ Physique des Milieux Condensés \\ IMPMC -IRD-CNRS UMR 7590 \\ Université Paris Pierre et Marie \\ Curie, Paris, France
}

Correspondence: Sylvie Crauste-Manciet Chemical, Genetic and Imaging Pharmacology Laboratory, INSERM UI022, CNRS UMR8I5I, Chimie ParisTech, Faculty of Pharmacy, Paris Descartes University, 4 Avenue de l'Observatoire, F-75006 Paris, France Tel +33 I 53739766

Fax +33 । 39274470

Email sylvie.crauste-manciet@ parisdescartes.fr

\begin{abstract}
Three multiple water-in-oil-in-water $(\mathrm{W} / \mathrm{O} / \mathrm{W})$ nanoemulsions have been designed for potential inclusion of either lipophilic or hydrophilic drugs using a two-step emulsification process exclusively based on low-energy self-emulsification. The W/O primary emulsion was constituted by a blend of oil (medium chain triglyceride), a mixture (7:3) of two surfactants, and a $10 \%$ water phase. The surfactants were a mixture of Polysorbate- $85 /$ Labrasol $^{\circledR}$, Polysorbate- $85 /$ Cremophor ${ }^{\circledR}$ EL or glycerol/Polysorbate-85. The final W/O/W nanoemulsions were obtained by the addition of water, with a weight ratio nanoemulsion/water of 1:2. The multiple emulsion stability was found to increase from 24 hours to 2 and 6 months with Labrasol, glycerol, and Cremophor, respectively. Cytotoxicity was found for formulations including Labrasol and Cremophor EL. The concentration of emulsion inhibiting 50\% cell viability $\left(\mathrm{IC}_{50}\right)$ was determined using the alamarBlue ${ }^{\circledR}$ test, giving after 24 hours of incubation, $\mathrm{IC}_{50}=10.2 \mathrm{mg} / \mathrm{mL}$ for the Labrasol formulation and $\mathrm{IC}_{50}=11.8 \mathrm{mg} / \mathrm{mL}$ for the Cremophor EL formulation. Corresponding calculated $\mathrm{IC}_{50}$ values for surfactants were $0.51 \mathrm{mg} / \mathrm{mL}$ for Labrasol and $0.59 \mathrm{mg} / \mathrm{mL}$ for Cremophor EL. In both cases, cytotoxicity was due to an apoptotic mechanism, evidenced by chromatin condensation and $\mathrm{P} 2 \mathrm{X} 7$ cell death receptor activation. The formulation including glycerol, investigated between 1 and $100 \mathrm{mg} / \mathrm{mL}$ concentration of nanoemulsion, did not affect cell viability. Moreover, neither chromatin condensation nor P2X7 activation was found between the 10 and $30 \mathrm{mg} / \mathrm{mL}$ final concentration of the emulsion. This last formulation would therefore be of major interest for further developments.
\end{abstract}

Keywords: Labrasol, Cremophor EL, apoptosis, P2X7 receptor, polysorbate, glycerol

\section{Introduction}

Nanoemulsions have been developed over the last decade for their particular interest for drug delivery through different routes. ${ }^{1-3}$ Multiple emulsions, such as water-in-oil-inwater $(\mathrm{W} / \mathrm{O} / \mathrm{W})$, have been less developed as drug carriers. These systems, also called double emulsion, are emulsions within an emulsion and consist of a primary water-inoil (W/O) emulsion of water droplets dispersed in oil droplets, which are themselves dispersed in an external water, giving the W/O/W multiple emulsion (schematically represented in Figure 1). The first major advantage of the multiple system is that it allows the absorption, via the enteric route, of poorly absorbed hydrophilic compounds, such as insulin. ${ }^{4}$ The second advantage is its potential for the co-delivery of drugs, giving the opportunity to carry hydrophilic and lipophilic compounds simultaneously in one single vehicle. ${ }^{5}$ The main drawback is the poor stability of the multiple systems due to their thermodynamic instability, but this can be enhanced by alteration in the size of the micrometer droplets. Nevertheless, multiple nanoemulsion systems have 


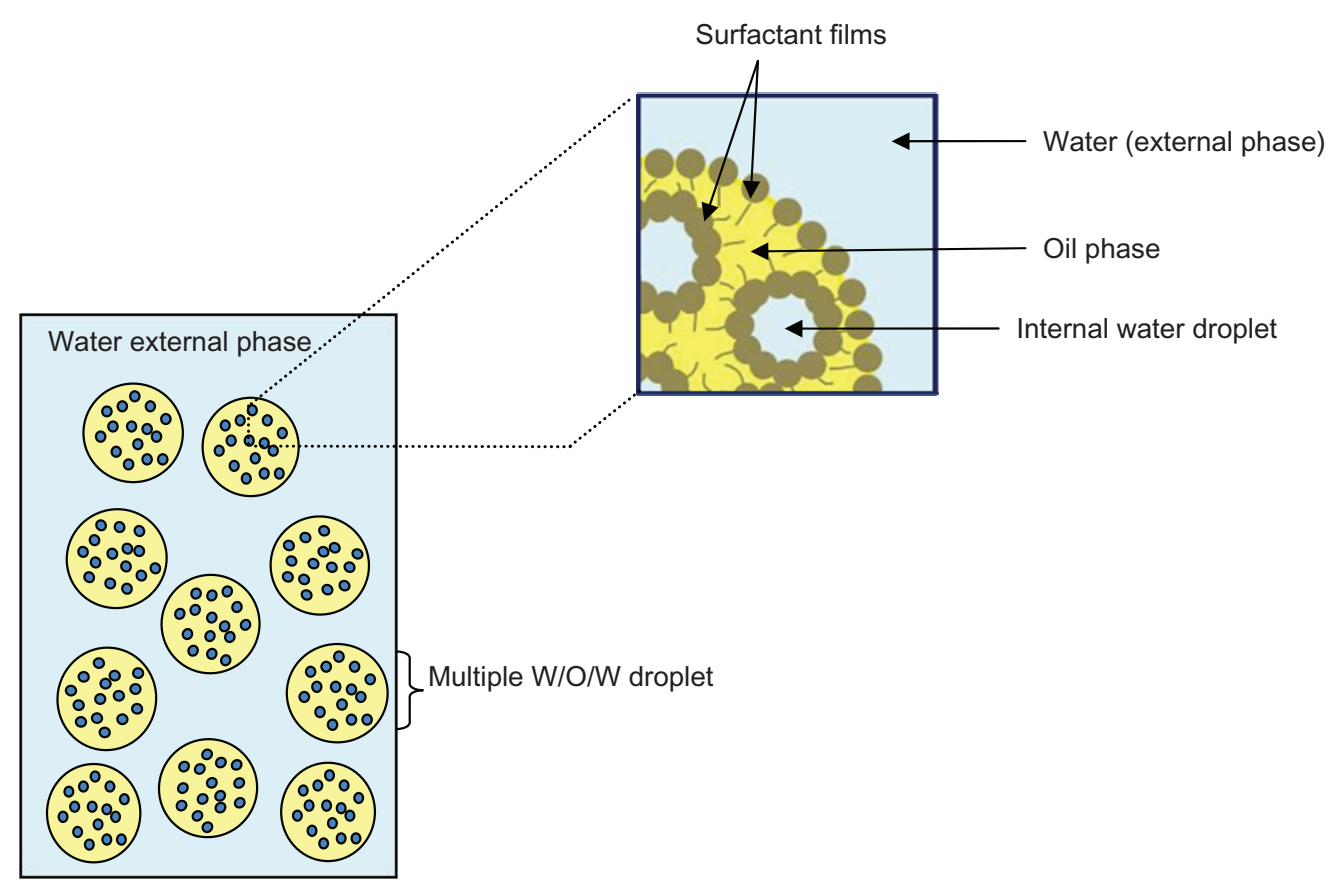

Figure I Schematic representation of W/O/W multiple emulsion. Abbreviation: W/O/W, water-in-oil-in-water.

been recently developed as drug carriers ${ }^{6}$ and have shown better stability to particle aggregation, due to small droplet size. ${ }^{7}$ However, these later systems still exhibited short-term stability, with quick enhancement of their mean droplet size within 7 days of observation.

Usually, a two-step emulsification process is required to obtain multiple emulsions, with a first process leading to the $\mathrm{W} / \mathrm{O}$ emulsion, followed by a second emulsification step leading to the final $\mathrm{W} / \mathrm{O} / \mathrm{W}$ emulsion. ${ }^{8}$ More recently, a one-step emulsification has been developed, which forms multiple droplets in the microscale range. ${ }^{9}$ A two-step emulsification process able to give multiple nanoemulsions requires high energy input, which limits their application to thermoresistant drugs. ${ }^{10}$ For sensitive drugs, such as proteins, an alternative is the use of low-energy processes that have been developed for $\mathrm{O} / \mathrm{W}$ nanoemulsion systems, based on a self-emulsification method. ${ }^{11-13}$ Multiple W/O/W emulsions have been obtained by self-emulsification but have exhibited very large droplet size (around $40-150 \mu \mathrm{m}) .{ }^{14}$ To the best of our knowledge, multiple nanoemulsion systems obtained by self-emulsification, thus giving multiple droplets in the nanoscale range, have not yet been developed. The main drawback of the self-emulsifying method, in comparison with the high-energy methods for producing nanoemulsions, is its use of great amounts of synthetic surfactants, which can lead to toxic effects and hence limit its choice as a route of administration..$^{15}$
The objective of the present work was to design original multiple nanoemulsions following a self-emulsifying method and assess their respective in vitro cytotoxicities, so as to consider their possible development for intravenous (IV) and/or oral routes of administration.

\section{Materials and methods Materials}

Polysorbate-85, polyoxyethylene 20 sorbitan trioleate (Montanox ${ }^{\circledR} 85$ ) was provided by Seppic Inc (Paris, France). Caprylocaproyl macrogol-8-glyceride $\left(\right.$ Labrasol $\left.^{\circledR}\right)$ was kindly provided from Gattefossé (St Priest, France), medium chain C8-C10 triglycerides from SIO (St Laurent Blangy, France), and polyoxyl 35 castor oil (Cremophor ${ }^{\circledR} \mathrm{EL}$ ) from BASF (Ludwigshafen, Germany). Glycerol was provided by Fagron Nordic A/S (Rotterdam, The Netherlands). All other reagents were of pharmaceutical grade.

Reagents for cell culture were provided by Eurobio SA (Montpellier, France). alamarBlue ${ }^{\circledR}$ was provided by SigmaAldrich (St Louis, MO, USA). Hoechst 33342 and YO$\mathrm{PRO}^{\circledR}$-1 were purchased from Life Technologies (Carlsbad, CA, USA).

\section{Multiple W/O/W nanoemulsion preparation}

Multiple $\mathrm{W} / \mathrm{O} / \mathrm{W}$ nanoemulsions were prepared using a two-step emulsification process: a first step to form the 
primary emulsions $(\mathrm{W} / \mathrm{O})$ and a second step to form multiple nanoemulsions (W/O/W) (Figure 2).

\section{Primary W/O nanoemulsion}

A blend of oil and surfactants was firstly mixed with a highshear mixer (Ultra-Turrax ${ }^{\circledR}$ T 25 basic; Ika-Werke GMBH and Co, Staufen, Germany) at 13,500 rpm for 15 minutes. $\mathrm{W} / \mathrm{O}$ nanoemulsions were formed by admixing water with oil and a surfactant blend, with gentle vortex stirring to ensure thorough mixing.

\section{Final multiple $\mathrm{W} / \mathrm{O} / \mathrm{W}$ nanoemulsion}

The previous $\mathrm{W} / \mathrm{O}$ nanoemulsion was directly added to water, with a weight ratio nanoemulsion/water of 1:2.

\section{Multiple W/O/W nanoemulsion formulations}

Different formulations of coupled surfactant/cosurfactant systems were developed, based on titration of the $\mathrm{W} / \mathrm{O}$ primary emulsion, which was expected to give a clear, transparent isotropic formulation, the so-called microemulsion. ${ }^{15}$ Pseudoternary phase diagrams were constructed for the Polysorbate-85/Labrasol surfactants, using weight ratios of $6: 4,7: 3,8: 2$, and 9:1. For the two other systems (Polysorbate-85/Cremophor EL and glycerol/Polysorbate-85) and based on the results of the first formulations, only the three main weight ratios (surfactant/ cosurfactant) of 7:3, 8:2, 9:1 were investigated for the selection of the optimal formulation.

When performed, pseudoternary phase diagrams were developed using the titration method, and temperature was controlled with a $25^{\circ} \mathrm{C}$ water bath. For each phase diagram, different weight ratios of oil and mixed surfactant/ cosurfactant were investigated: 10:0, 9:1, 8:2, 7:3, 6:4, 5:5, $4: 6,3: 7,2: 8,1: 9$, and $0: 10(\mathrm{w} / \mathrm{w})$. Slow titration with the aqueous phase was performed for each weight ratio of oil and mixed surfactant/cosurfactant, and visual observation was carried out for a clear transparent W/O microemulsion. Once stable transparent formulations were obtained, simple tests of nondispersibility in water and conductance tests were conducted to confirm that they were $\mathrm{W} / \mathrm{O}$ microemulsions. In addition, the $\mathrm{W} / \mathrm{O}$ microemulsions were observed under polarizing light and found to be nonbirefringent, as expected from their isotropic nature. The physical state of the microemulsion was marked using the ProSim Ternary Diagram computer program (ProSim, Labège, France), on

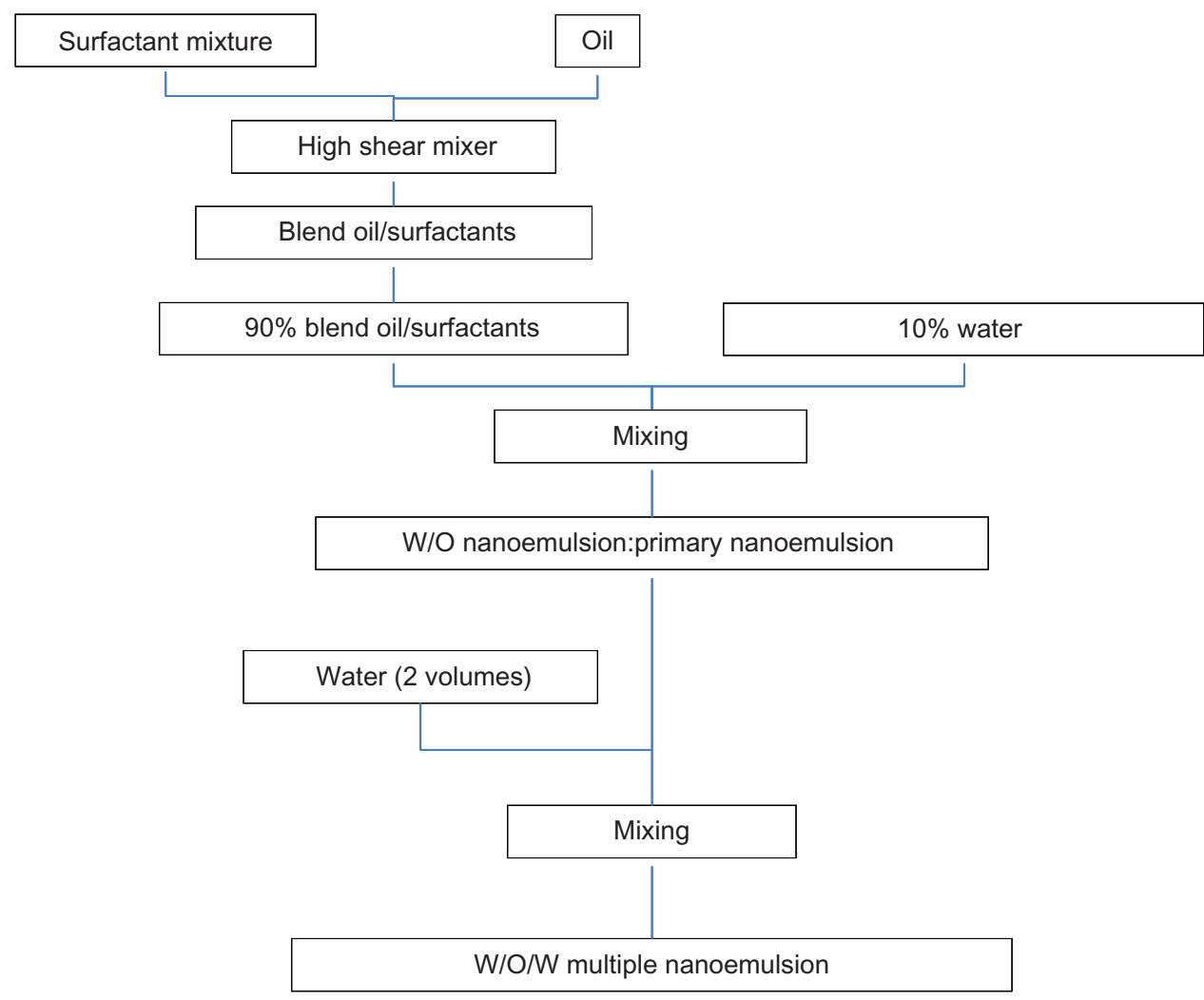

Figure 2 Schematic representation of W/O/W nanoemulsion preparation. Abbreviations: W/O/W, water-in-oil-in-water; W/O, water-in-oil. 
a pseudo-three-component phase diagram, with one axis representing the aqueous phase, another representing oil, and the third axis representing the mixture of surfactant and cosurfactant at fixed weight ratios. The selection of the best surfactant/cosurfactant systems was orientated to the highest surface of the microemulsion phase from pseudoternary phase diagrams. Twenty-seven formulations within the pseudoternary phase diagrams were produced.

\section{Physical characterization of $\mathrm{W} / \mathrm{O} / \mathrm{W}$ nanoemulsion systems \\ Macroscopic observation}

The macroscopic homogeneity of the final W/O/W multiple nanoemulsions was assessed for 6 months.

\section{Droplet-size measurement}

The mean multiple droplet size and polydispersity index (PDI) of multiple droplets were determined by dynamic light scattering (Zetasizer Nano-SZ ${ }^{\circledR}$; Malvern Instruments Ltd, Malvern, UK). Prior to measurement, to avoid multiple scattering effects, the multiple $\mathrm{W} / \mathrm{O} / \mathrm{W}$ emulsions were diluted in water $(1: 100)$. The measurements were performed at $25^{\circ} \mathrm{C}$, at a fixed scatter angle of $173^{\circ}$, directly after the sample dilution and were expressed as mean \pm standard deviation (SD) $(n=3)$. The PDI was a dimensionless measure of the width of the size distribution, calculated from the cumulant analysis ranging from 0 to 1 . A small value of $\mathrm{PDI}$, usually $<0.2$, is indicative of a monodisperse population.

\section{Zeta potential measurement}

The zeta potential was obtained from electrophoretic mobility measurements using a Zetasizer Nano-SZ ${ }^{\circledR}$ (Malvern Instruments Ltd). Prior to measurements, the samples were diluted 1:250 with sodium chloride $1 \mathrm{mM}$ to maintain conductivity constant at $0.140 \mathrm{mS} \mathrm{cm}{ }^{-1}$. Measurements were performed directly after the samples were diluted (and were expressed as mean $\pm \mathrm{SD},[\mathrm{n}=3])$, at $25^{\circ} \mathrm{C}$.

\section{$\mathrm{pH}$ measurement}

The $\mathrm{pH}$ was determined for each formulation (PHM210 standard $\mathrm{pH}$ Meter, Radiometer Analytical, Copenhagen, Denmark), at $25^{\circ} \mathrm{C}$. Measurements were realized in triplicate (and expressed as mean $\pm \mathrm{SD}[\mathrm{n}=3]$ ).

\section{Osmolality measurement}

The osmolality of the different formulations was measured using Fiske ${ }^{\circledR}$ Mark 3 osmometer, (Advanced
Instruments Inc, Norwood, MA, USA). Measurements were realized in triplicate and were expressed as mean $\pm \mathrm{SD}$ $(n=3)$.

\section{Transmission electron microscopy (TEM)}

The multiple W/O/W emulsions were observed by TEM. For this, $5 \mu \mathrm{L}$ of sample was deposited on a carbon-coated grid and adsorbed. Then, $5 \mu \mathrm{L}$ of uranyl acetate (negative stain) was applied to this and rapidly absorbed. The sample analysis was performed with a JEOL JEM 2100 (JEOL Ltd, Tokyo, Japan) TEM operating at $200 \mathrm{kV}$ and magnifications of $\times 20,000$, $\times 40,000$, and $\times 100,000$. Images were recorded using a $2 \mathrm{k}$ Ultrascan ${ }^{\circledR} 1000$ CCD Gatan camera (Gatan Inc, Pleasanton, CA, USA).

\section{Stability study}

The stability of the multiple $\mathrm{W} / \mathrm{O} / \mathrm{W}$ nanoemulsion was evaluated by size distribution measurements by dynamic light scattering (and expressed as mean $\pm \mathrm{SD}[\mathrm{n}=3]$ ) at ambient temperature for 6 months; and by visual observation of macroscopic changes, such as phase separation or creaming. The short-term stability of the multiple nanoemulsions was assessed after dilution (1:1) of the $\mathrm{W} / \mathrm{O} / \mathrm{W}$ nanoemulsions with an aqueous solution simulating gastric $\mathrm{pH} 1.2(\mathrm{HCl}$, $\mathrm{NaCl}$ solution) or intestinal pH 6.8 (phosphate buffer, $\mathrm{NaOH}$ solution). Stability was assessed by visual observation and by measurement of size distribution by dynamic light scattering (expressed as mean $\pm \mathrm{SD}[\mathrm{n}=3]$ ) at time zero and 2 hours after contact.

\section{Cytotoxicity assay}

\section{Cell culture}

Cell culture was run on a human ocular epithelial cell line (Wong Kilbourne Derivative; European Collection of Cell Cultures [ECACC] 93120839; Salisbury, UK). Cells were cultured under standard conditions (moist atmosphere of $5 \% \mathrm{CO}_{2}$, at $37^{\circ} \mathrm{C}$ ) in Dulbecco's minimum essential medium (DMEM). DMEM was supplemented with $2.5 \%$ (for cytotoxicity assays) or $10 \%$ of fetal bovine serum (for cell proliferation), $2 \mathrm{mM}$ L-glutamine, $50 \mathrm{UI} / \mathrm{mL}$ penicillin, and $50 \mathrm{UI} / \mathrm{mL}$ streptomycin. The medium was changed every three days. Confluent cultures were removed by trypsin incubation, and cells were seeded $(200 \mu \mathrm{L}$ per well) into $96-w e l l$ culture microplates at a density of 110,000 cells $/ \mathrm{mL}$. The cultures were kept at $37^{\circ} \mathrm{C}$ for 24 hours prior to emulsion exposure, to allow the cells to attach to the microplate and reach confluency. 


\section{Cell viability}

Cell viability and necrotic cells were determined using the alamarBlue ${ }^{\circledR}$ test. ${ }^{16}$ The tested emulsions were previously diluted at nine different concentrations in culture medium supplemented with $2.5 \%$ of fetal bovine serum. Prior to incubation, the cells were washed with $200 \mu \mathrm{L}$ phosphatebuffered saline (PBS); then, $100 \mu \mathrm{L}$ of each dilution of emulsion was distributed in the wells, and plates were incubated for 1 hour or 24 hours at $37^{\circ} \mathrm{C}$. After incubation times ( 1 and 24 hours), emulsions were removed, and the cells were rinsed with $200 \mu \mathrm{L}$ of PBS. The alamarBlue dye solution $(200 \mu \mathrm{L})$ was then added to each well for 6 hours incubation at $37^{\circ} \mathrm{C}$. The alamarBlue dye solution had been previously diluted at $0.09 \mathrm{mg} / \mathrm{mL}$ in the culture medium supplemented with $2.5 \%$ fetal bovine serum. AlamarBlue fluorescence $\left(\lambda_{\mathrm{ex}}=535 \mathrm{~nm}\right.$; $\lambda_{\mathrm{em}}=600 \mathrm{~nm}$ ) was measured using a cytofluorometer (Safire; Tecan Group Ltd, Männedorf, Switzerland) adapted to the microplates. Results were obtained in fluorescence intensity and were expressed as percentage of viable cells compared with the control without nanoemulsion. ${ }^{17,18}$

\section{Apoptosis assessments}

For apoptosis assessment, the tested emulsions were diluted at ratios of 1/35, 1/50, and 1/100 in culture medium (supplemented with $2.5 \%$ fetal bovine serum), as determined by the cell viability test (alamarBlue test). For apoptosis assessment, we performed cytometric apoptosis analysis and used propidium iodide counterstaining for all DNA probes, to discriminate the necrotic mechanism, according to the recommendations by Darzynkiewicz et $\mathrm{al}^{19}$ and Darzynkiewicz and Huang. ${ }^{20}$

\section{Apoptosis assessment by chromatin condensation (Hoechst 33342 test)}

Hoechst 33342 is a probe that can evaluate chromatin condensation. ${ }^{21}$ Propidium iodide was used to discriminate necrotic cells. The tested emulsions were previously diluted in culture medium supplemented with $2.5 \%$ fetal bovine serum at ratios of $1 / 35,1 / 50$, and $1 / 100$. Prior to incubation, the cells were washed with $200 \mu \mathrm{L}$ PBS; then, $100 \mu \mathrm{L}$ of each sample was incubated in wells for 1 and 24 hours. At the end of incubation times, the cells were washed with PBS $(200 \mu \mathrm{L})$. To overcome the risk of apoptotic induction by the Hoechst 33342 probe itself at high concentration, ${ }^{22,23}$ we used a low concentration and short incubation time of 30 minutes for the apoptosis analysis, in accordance with Rat et $\mathrm{al}^{24,25}$ and the guidelines described in Galluzzi et al. ${ }^{26}$ Then, $10 \mu \mathrm{g} / \mathrm{mL}$ Hoechst 33342 solution in PBS containing $0.05 \mathrm{mg} / \mathrm{mL}$ propidium iodide was distributed in wells $(200 \mu \mathrm{L}$ per well). The plates were incubated at room temperature for 30 minutes in the dark. Hoechst fluorescence $\left(\lambda_{\text {ex }}=360 \mathrm{~nm} ; \lambda_{\text {em }}=450 \mathrm{~nm}\right.$ ) was directly measured using a microplate cytofluorometer according to P Rat protocol. ${ }^{24}$ The Hoechst fluorescent signal was then observed by inverted fluorescence microscopy (DMIRB; Leica Microsystems, Wetzlar, Germany) and photographed (Coolpix 5000; Nikon, Tokyo, Japan). Results were obtained in fluorescence intensity reported to the fluorescence intensity of the control, giving the percentage of dead cells. To take into account the number of living cells after incubation, results were expressed as a fluorescence ratio of Hoechst/ viable cells (alamarBlue), this ratio being the percentage of dead cells obtained by Hoechst reported to the percentage of viable cells obtained with alamarBlue test, at the same final concentration of nanoemulsion.

\section{Apoptosis assessment by $\mathrm{P} 2 \mathrm{X} 7$ cell death receptor activation (YO-PRO-1 test)}

YO-PRO-1 stain is a DNA probe used with flow cytometry and fluorescence microscopy to discriminate cells dying by apoptosis from those dying by necrosis. ${ }^{27}$ This probe enters apoptotic cells after $\mathrm{P} 2 \mathrm{X} 7$ receptor activation (which leads to the formation of apoptotic membrane pores). ${ }^{28,29}$ YO-PRO-1 is a nuclear dye that does not label living cells. ${ }^{27}$ The tested emulsions were diluted in culture medium (supplemented with $2.5 \%$ fetal bovine serum) at the same dilution levels as those used in the Hoechst 33342 test. Prior to incubation, the cells were washed with $200 \mu \mathrm{L}$ PBS; then, $100 \mu \mathrm{L}$ of each sample was incubated in wells for 1 and 24 hours. At the end of incubation times, the cells were rinsed with PBS $(200 \mu \mathrm{L})$ and $2 \mu \mathrm{MYO}-\mathrm{PRO}-1$ solution in PBS was directly distributed in the 96-well microplates ( $200 \mu \mathrm{L}$ per well) according to the protocol of Dutot et al. ${ }^{28}$ The microplates were incubated at room temperature for 10 minutes in the dark. The YO-PRO-1 fluorescent signal was then observed by inverted fluorescence microscopy and photographed. Results were obtained in fluorescence intensity reported to the fluorescence intensity of the control, giving the percentage of dead cells. To take into account the number of living cells after incubation, results were expressed as a fluorescence ratio YO-PRO-1/ viable cells (alamarBlue), this ratio being the percentage of dead cells obtained by YO-PRO-1 reported to the percentage of viable cells obtained by the alamarBlue test, at the same final concentration of nanoemulsion. 


\section{Statistical analysis}

Each dilution of emulsion was tested in six wells, and each experiment was realized in triplicate. The mean values for each concentration were analyzed by a one-way analysis of variance (ANOVA), followed by Dunnett's test. ${ }^{30,31}$ The level of significance was fixed at 0.05 . Statistical analysis was performed using SigmaStat 2.0 software (Systat Software Inc, San Jose, CA, USA).

\section{Results}

\section{Selection of the formulation systems}

The results of pseudoternary phase diagram studies performed for Polysorbate-85/Labrasol formulations are shown in Figure 3. Four pseudoternary phase diagrams of surfactant mixtures (Polysorbate-85/Labrasol with ratios of [A] 9:1, [B] 8:2, [C] 7:3, and [D] 6:4), medium chain triglyceride oil, and water were obtained. The diagrams show an increased area of W/O microemulsion zones, with a shifting towards the water rich regions, upon increased ratio of Labrasol in the surfactant/ cosurfactant mixture. But the nonmicroemulsion oil dispersion phase formed between oil-surfactant axes and the microemulsion phase increased with the Labrasol ratio. All in all, the surfactant/ cosurfactant ratio 7:3 gave the highest microemulsion surface of $20.3 \%$ in comparison with $13.9 \%, 16.3 \%$, and $17.9 \%$ obtained for the ratios $6: 4,9: 1$, and $8: 2$, respectively.

According to the best area results found with the 7:3, 8:2, 9:1 systems, the formulations where Labrasol was
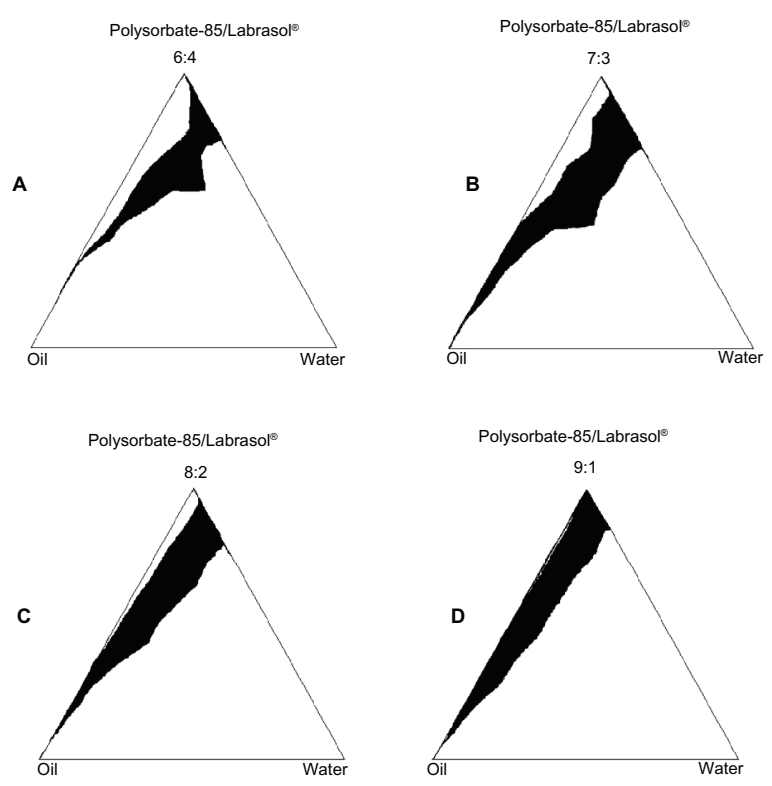

Figure 3 Pseudoternary phase diagrams of Polysorbate-85/Labrasol ${ }^{\circledR}$, oil (MCT) and water, with different ratios of Polysorbate-85:Labrasol ${ }^{\circledR}$. (A) 6:4; (B) 7:3; (C) 8:2; (D) 9:1.

Note: $\mathbf{\square}=$ microemulsion phase

Abbreviation: MCT, medium chain triglycerides. substituted by Cremophor EL were confirmed to be in the microemulsion domain, giving a homogenous and translucent system for all W/O primary systems. For the nanoemulsion including glycerol, the W/O primary emulsion was homogenous but exhibited a light haze whatever the system used (9:1, 8:2, or 7:3), due to the large amount of glycerol. Compositions of the selected primary $\mathrm{W} / \mathrm{O}$ emulsions are given in Table 1.

With regard to the final $\mathrm{W} / \mathrm{O} / \mathrm{W}$ nanoemulsions, Table 2 gives the granulometric results and visual aspects of the multiple $\mathrm{W} / \mathrm{O} / \mathrm{W}$ nanoemulsions immediately after emulsification. Among the three surfactant ratios investigated, the 7:3 systems of Polysorbate-85/Labrasol; Polysorbate-85/ Cremophor EL; and glycerol/Polysorbate- 85 gave the best granulometric results, in comparison with the 8:2 and 9:1 systems. Moreover, in terms of stability, the best formulation was the Polysorbate-85/Cremophor EL system that exhibited the same granulometric characteristics for more than 3 months. Visual color change, ie, whitening, was observed at 6 months, with a granulometric enlargement of $210.6 \pm 9.5 \mathrm{~nm}$ (PDI: $0.086 \pm 0.043)$ but remaining still within the nanometric scale. Conversely, the worst stability level was observed with the Polysorbate-85/Labrasol systems, where fast phase separation was visually observed within 24 hours, with dramatic enlargement of the droplet sizes to $1080 \pm 54 \mathrm{~nm}$ (PDI: $0.281 \pm 0.045$ ). The tendency toward instability was enhanced when the surfactant ratios used were in the $8: 2$ and 9:1 systems, with phase separation observed within 12 hours and 5 hours, respectively. The glycerol/Polysorbate- 85 system exhibited an intermediate behavior in terms of stability, with a stability of granulometric parameters for 1 month; and an enlargement of droplet size beginning at 2 months, with creaming and enlargement of droplet size to $664.00 \pm 38.32 \mathrm{~nm}$ (PDI: $0.101 \pm 0.045$ ). Moreover, the 8:2 and 9:1 systems showed dramatic enlargements over time, with droplet size above $1.5 \mu \mathrm{m}$ and polydispersity indexes above 0.2 .

Table I Composition (\%) of selected primary W/O nanoemulsions

\begin{tabular}{|c|c|c|c|c|c|c|c|c|c|}
\hline \multirow{2}{*}{$\begin{array}{l}\text { Surfactant ratio } \\
\text { Formulation ID }\end{array}$} & \multicolumn{3}{|c|}{$7: 3$} & \multicolumn{3}{|c|}{$8: 2$} & \multicolumn{3}{|l|}{ 9:1 } \\
\hline & $\mathbf{A}$ & B & C & $A^{\prime}$ & $\mathbf{B}^{\prime}$ & $\mathbf{C}^{\prime}$ & $A^{\prime \prime}$ & $\mathbf{B}^{\prime \prime}$ & $C^{\prime \prime}$ \\
\hline Polysorbate-85 & 35 & 35 & 15 & 40 & 40 & 10 & 45 & 45 & 5 \\
\hline Labrasol $^{\circledR}$ & 15 & - & - & 10 & - & - & 5 & - & - \\
\hline Cremophor $^{\circledR}$ EL & - & 15 & - & - & 10 & - & - & 5 & - \\
\hline Glycerol & - & - & 35 & - & - & 40 & - & - & 45 \\
\hline $\begin{array}{l}\text { Oil:medium chain } \\
\text { triglyceride }\end{array}$ & 40 & 40 & 40 & 40 & 40 & 40 & 40 & 40 & 40 \\
\hline Water & 10 & 10 & 10 & 10 & 10 & 10 & 10 & 10 & 10 \\
\hline
\end{tabular}

Abbreviation: W/O, water-in-oil. 
Table 2 Granulometric characteristics and visual aspect of W/O/W multiple nanoemulsions immediately after emulsification

\begin{tabular}{lllll}
\hline Nanoemulsion & $\begin{array}{l}\text { Surfactant } \\
\text { ratio }\end{array}$ & MDS $(\mathbf{n m})^{\mathbf{a}}$ & PDI $^{\mathbf{a}}$ & $\begin{array}{l}\text { Visual observation } \\
\text { of W/O/W final emulsion }\end{array}$ \\
\hline A & $7: 3$ & $154.14 \pm 1.21$ & $0.062 \pm 0.050$ & White \\
B & $7: 3$ & $40.46 \pm 0.20$ & $0.099 \pm 0.007$ & Bluish translucent \\
C & $7: 3$ & $196.40 \pm 4.39$ & $0.202 \pm 0.110$ & White \\
$A^{\prime}$ & $8: 2$ & $156.30 \pm 0.40$ & $0.183 \pm 0.060$ & White \\
$B^{\prime}$ & $8: 2$ & $46.65 \pm 0.17$ & $0.117 \pm 0.005$ & Bluish translucent \\
$C^{\prime}$ & $8: 2$ & $475.90 \pm 25.50$ & $0.543 \pm 0.150$ & White \\
$A^{\prime \prime}$ & $9: 1$ & $196.60 \pm 1.50$ & $0.244 \pm 0.06$ & White \\
$B^{\prime \prime}$ & $9: 1$ & $193.00 \pm 0.36$ & $0.228 \pm 0.013$ & White \\
$C^{\prime \prime}$ & $9: 1$ & $976.00 \pm 342.00$ & $0.087 \pm 0.067$ & White \\
\hline
\end{tabular}

Notes: aData presented as mean value \pm standard error $(n=3)$.

Abbreviations: MDS, mean droplet size; PDI, polydispersity index; W/O/W, water in oil in water.

Therefore, with regard to granulometric characteristics and stability, the best formulations for the three sets of surfactants were obtained with the 7:3 surfactant ratio. These were selected for toxicological assessment and further characterizations, namely zeta potential and TEM.

\section{Multiple W/O/W nanoemulsion characterization}

The best three formulations (herein referred to as formulations $\mathrm{A}-\mathrm{C}$ ), selected previously, were characterized for zeta potential, $\mathrm{pH}$, osmolarity and TEM micrograph. Zeta potential was found to be close to neutrality, in particular for formulation A; the most negative potential was found with the glycerol/Polysorbate-85 surfactant system (Table 3).

With a view to their future applications, their $\mathrm{pH}$ was considered as compatible with parenteral administration, and does not have to be adjusted. Conversely, osmolality would need to be brought to isotonicity for the three formulations. The correction of osmolality can be done using a low concentration of glycerol (formulation A: $1.5 \%[\mathrm{w} / \mathrm{w}]$ and formulation B: $2.25 \%[\mathrm{w} / \mathrm{w}]$ ) and with the same concentration in the external and internal aqueous phases, to limit water exchange between the two phases. ${ }^{32,33}$ Formulation C, which was found to be hypertonic, would have to be diluted before parenteral administration. With the view to their potential administration via the oral route, a short term stability study, with $\mathrm{pH} 1.2$ and 6.8 aqueous solutions simulating gastric and

Table 3 Zeta potential and $\mathrm{pH}$ of the three formulations

\begin{tabular}{lll}
\hline Formulation & Zeta potential $(\mathrm{mV})$ & $\mathrm{pH}$ \\
\hline A & $-1.2 \pm 0.3$ & $5.5 \pm 0.1$ \\
B & $-2.3 \pm 0.2$ & $6.4 \pm 0.1$ \\
C & $-6.0 \pm 0.1$ & $5.8 \pm 0.1$ \\
\hline
\end{tabular}

Note: A: Polysorbate-85/Labrasol ${ }^{\circledR}$; B: Polysorbate-85/Cremophor ${ }^{\circledR}$ EL; C: glycerol/Polysorbate-85. intestinal $\mathrm{pH}$, respectively, showed no modification of their macroscopic aspects and no creaming, precipitation, or phase separation during the 2 hours of observation. Apart from this, a very small enhancement of mean droplet sizes (Table 4) was observed in comparison with the reference formulation but never compromised the nanoscale range.

Figure 4 shows the TEM micrograph of the three formulations. Visualization of the internal droplets depended on the multiple droplet size; it was thus not possible to visualize internal droplets of the Cremophor EL/Polysorbate-85 systems (formulation B) that exhibited a very low size for the multiple droplets (around $40 \mathrm{~nm}$ ). Conversely, internal water droplets of around $10 \mathrm{~nm}$ were visualized in the glycerol/Polysorbate- 85 emulsions and to a lesser extent in the Labrasol/Polysorbate- 85 system. For those two systems, multiple droplet size was around 150-200 nm.

\section{Toxicological analysis} Cell viability

Cell viability results showed an important cytotoxicity for formulation A after 1 hour of incubation, with a decrease of $50 \%$ in cell viability for the concentration of $25.6 \mathrm{mg} / \mathrm{mL}$ of the emulsion, and after 24 hours of incubation, for the concentration of $10.2 \mathrm{mg} / \mathrm{mL}$ of the emulsion. For formulation B, an $\mathrm{IC}_{50}$ was not reached after 1 hour of incubation but was found after 24 hours of incubation, for the concentration of $11.8 \mathrm{mg} / \mathrm{mL}$ of the emulsion. Finally, for formulation $\mathrm{C}$, no cytotoxicity was detected both after 1 hour and 24 hours of incubation, with undeterminable $\mathrm{IC}_{50}$ values (Figure 5).

\section{Apoptosis assessment}

Three concentrations of the three formulations $(28.5,20$, and $10 \mathrm{mg} / \mathrm{mL}$ ) were chosen for apoptosis assessment. Figure 6 shows the results of the chromatin condensation test (Hoechst 33342), and Figure 7 shows the results of the P2X7 cell death receptor activation test (YO-PRO-1 test). 
Table 4 Granulometric parameters of W/O/W nanoemulsions with gastric and intestinal $\mathrm{pH}$-simulating aqueous solutions

\begin{tabular}{|c|c|c|c|c|}
\hline \multirow{2}{*}{$\begin{array}{l}\text { Formulation/ } \\
\text { observation time }\end{array}$} & \multicolumn{2}{|l|}{ pH 1.2} & \multicolumn{2}{|l|}{ pH 6.8} \\
\hline & MDS (nm) ${ }^{a}$ & PDI $(n m)^{a}$ & MDS (nm) ${ }^{a}$ & PDI $(n m)^{a}$ \\
\hline $\mathrm{A} / \mathrm{TO}$ & $177.30 \pm 3.06$ & $0.106 \pm 0.070$ & $211.60 \pm 6.56$ & $0.133 \pm 0.030$ \\
\hline $\mathrm{A} / \mathrm{T} 2 \mathrm{~h}$ & $201.90 \pm 2.51$ & $0.100 \pm 0.023$ & $230.30 \pm 6.45$ & $0.137 \pm 0.019$ \\
\hline B/T0 & $49.72 \pm 0.20$ & $0.150 \pm 0.022$ & $47.27 \pm 0.30$ & $0.138 \pm 0.012$ \\
\hline $\mathrm{B} / \mathrm{T} 2 \mathrm{~h}$ & $48.14 \pm 0.31$ & $0.108 \pm 0.062$ & $46,32 \pm 0.31$ & $0.112 \pm 0.003$ \\
\hline C/TO & $214.30 \pm 0.37$ & $0.352 \pm 0.054$ & $2|8.30 \pm| .5 \mid$ & $0.319 \pm 0.059$ \\
\hline $\mathrm{C} / \mathrm{T} 2 \mathrm{~h}$ & $210.90 \pm 3.54$ & $0.316 \pm 0.042$ & $213.40 \pm 4.05$ & $0.329 \pm 0.072$ \\
\hline
\end{tabular}

Note: a Data presented as mean value \pm standard error $(n=3)$. A: Polysorbate-85/Labrasol ${ }^{\circledast}$; B: Polysorbate-85/Cremophor ${ }^{\oplus}$ EL; C: glycerol/Polysorbate-85. Abbreviations: MDS, mean droplet size; PDI, polydispersity index; W/O/W, water-in-oil-in-water.
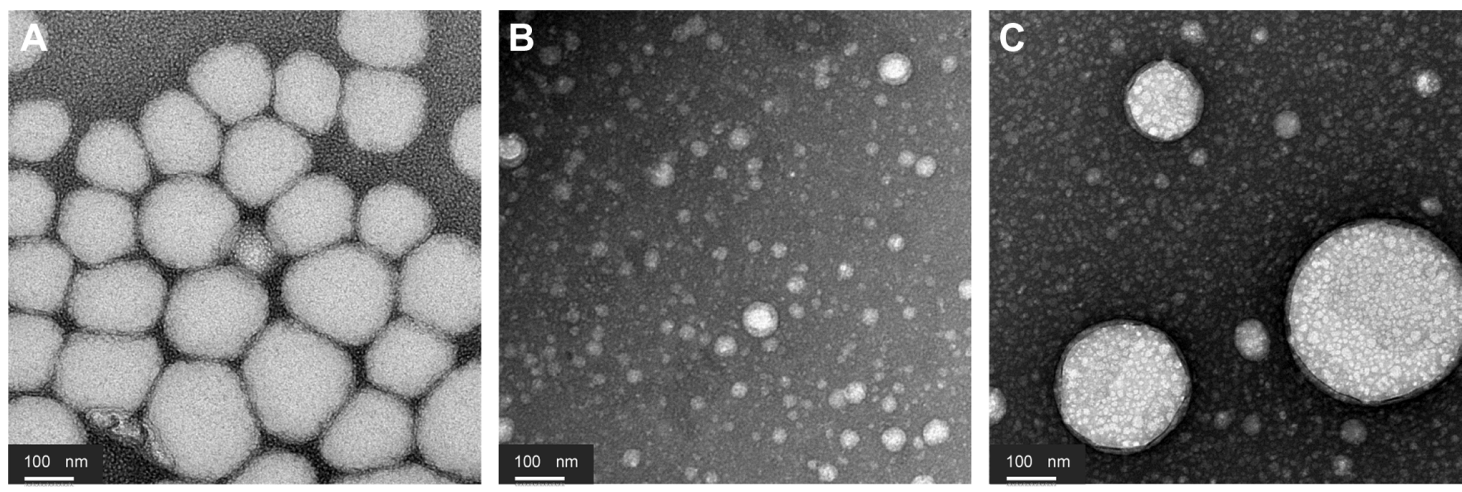

Figure 4 Transmission electron microscopy micrographs of W/O/W nanoemulsions. (A) Polysorbate-85/Labrasol ${ }^{\circledast}$; (B) Polysorbate-85/Cremophor ${ }^{\oplus}$ EL; (C) glycerol/ Polysorbate-85.

Abbreviation: W/O/W, water-in-oil-in-water.

1-hour incubation
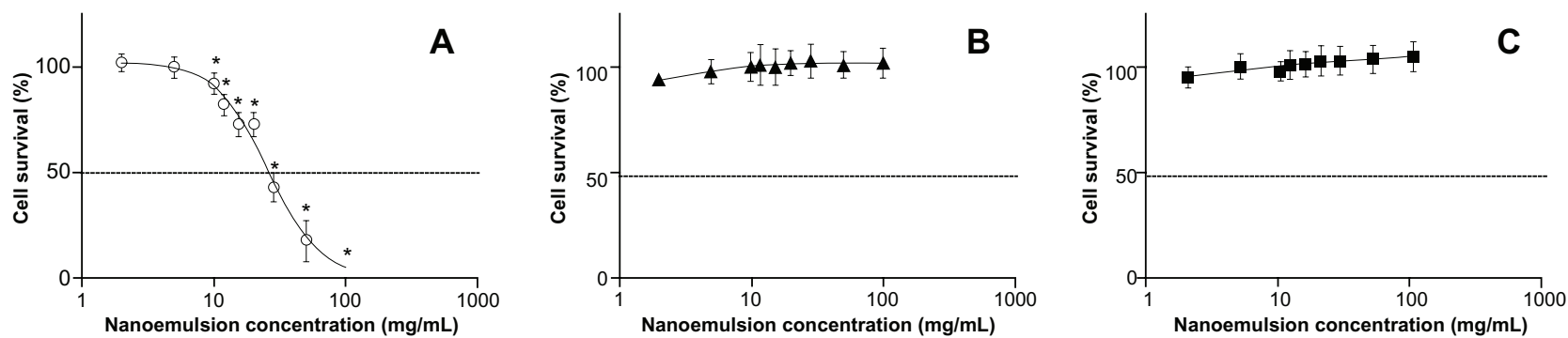

24-hour incubation
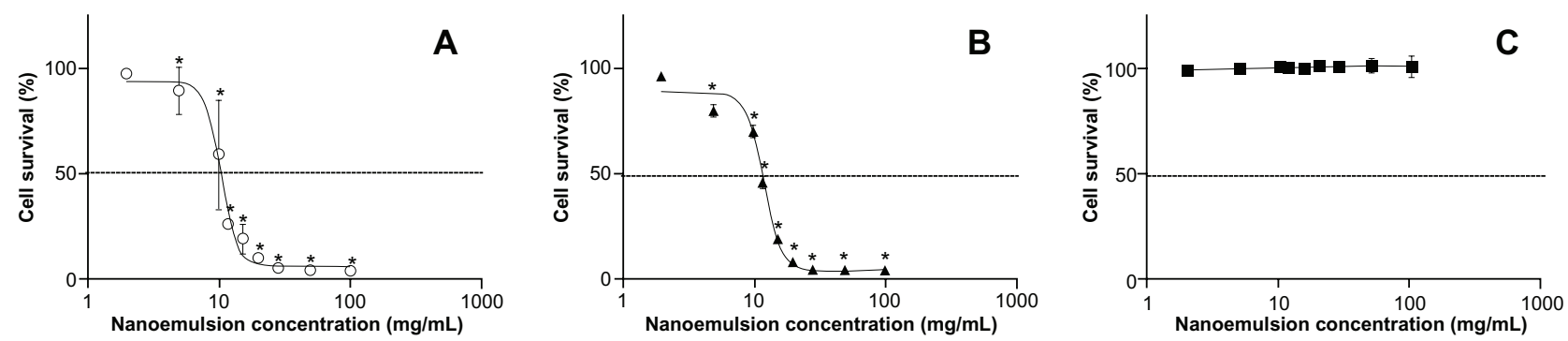

Figure 5 Cell viability of W/O/W nanoemulsion formulations using alamarBlue ${ }^{\circledR}$ test at I-hour and 24-hour incubation times. (A) Polysorbate-85/Labrasol ${ }^{\circledR}$; (B) Polysorbate-85/ Cremophor $^{\circledR}$ EL; (C) glycerol/Polysorbate-85.

Notes: Each value represents the mean and standard deviation $(n=3)$. *Cell viability was significantly $(P<0.00 I)$ below cell viability of the control without nanoemulsion. Abbreviation: $\mathrm{W} / \mathrm{O} / \mathrm{W}$, water-in-oil-in-water. 


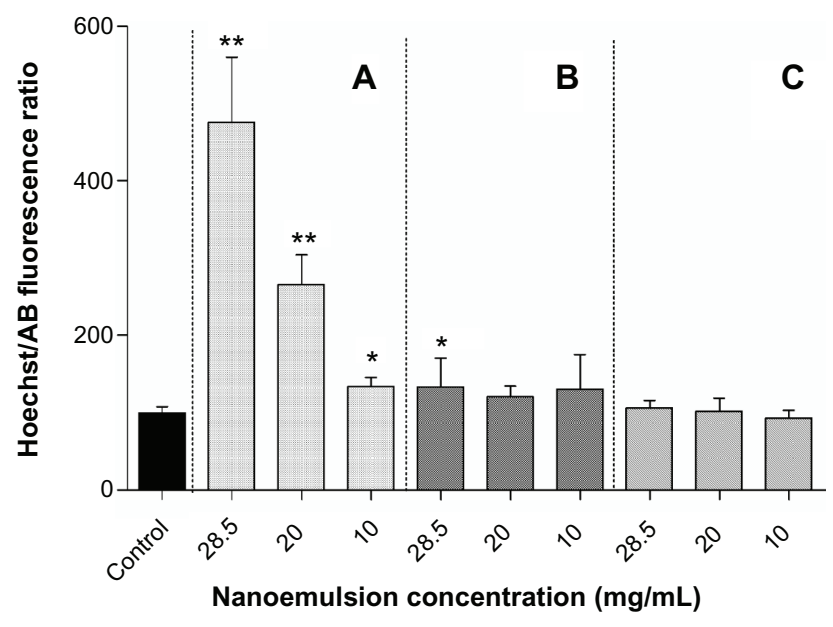

24-hour incubation

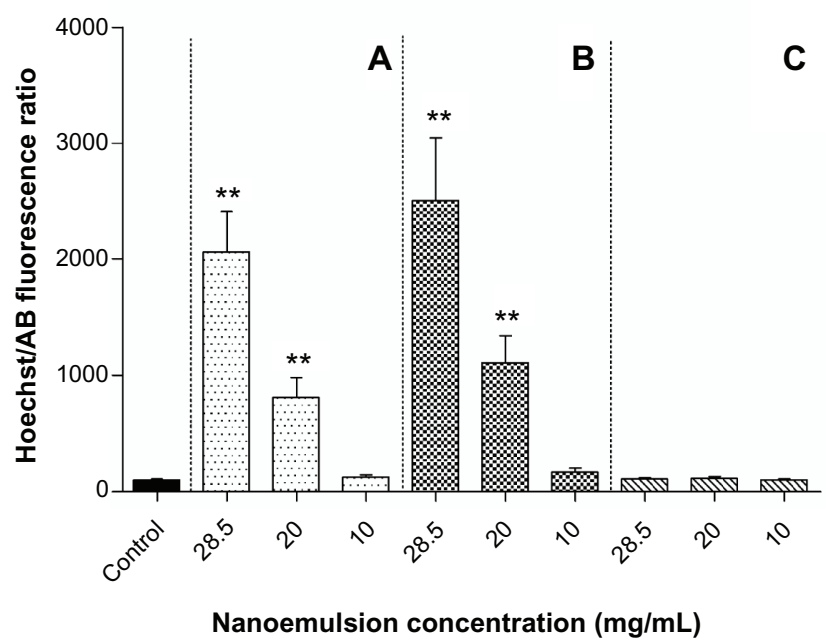

Figure 6 Apoptosis chromatin condensation assessment (Hoechst 33342 test) of W/O/W nanoemulsion formulations after I- and 24-hour incubation. $\begin{array}{lll}\text { (A) Polysorbate-85/Labrasol } & { }^{\circledR} \text {; } & \text { (B) Polysorbate-85/Cremophor }{ }^{\circledR} \quad \text { EL; }\end{array}$ (C) glycerol/Polysorbate-85.

Notes: Hoechst/AB ratio significantly (**P $<0.00$ I; $* P<0.05)$ compared with the control without nanoemulsion. Each value represents the mean and standard deviation $(\mathrm{n}=3)$.

Abbreviations: $A B$, alamarBlue ${ }^{\circledR} ; W / O / W$, water-in-oil-in-water.

With regard to the chromatin condensation test, formulation A exhibited significantly higher apoptosis ratios in comparison with the control, both after 1 hour of incubation ( $P<0.001$ for the three concentrations) and 24 hours of incubation $(P<0.001$ for the 28.5 and $20 \mathrm{mg} / \mathrm{mL}$ emulsion concentrations and $P<0.05$ for $10 \mathrm{mg} / \mathrm{mL}$ emulsion concentration). Apoptosis ratios (Hoechst/alamarBlue) decreased with the dilution, giving values for 1 hour of incubation of around 470, 260, and 130 for the 28.5, 20, and $10 \mathrm{mg} / \mathrm{mL}$ concentrations of emulsion, respectively and after 24 hours of incubation, around 2000, 800, and 120

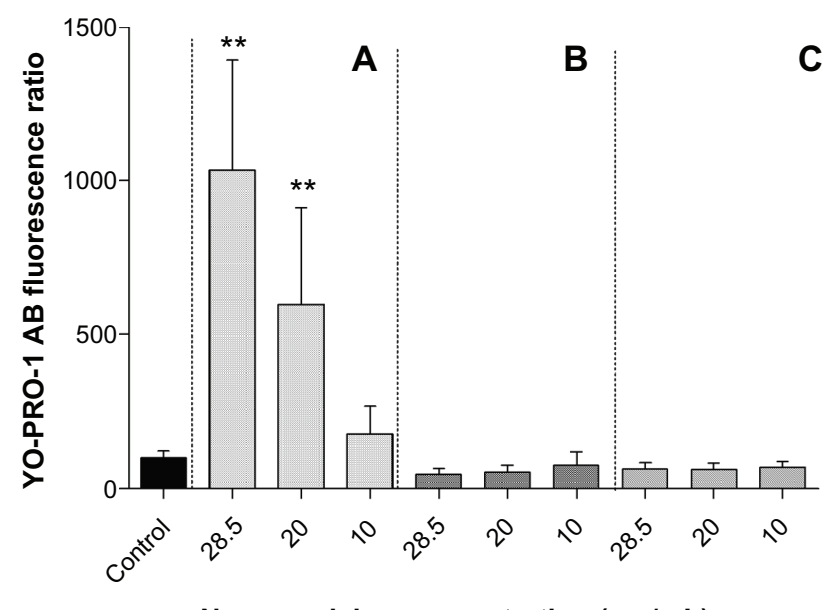

Nanoemulsion concentration $(\mathrm{mg} / \mathrm{mL})$

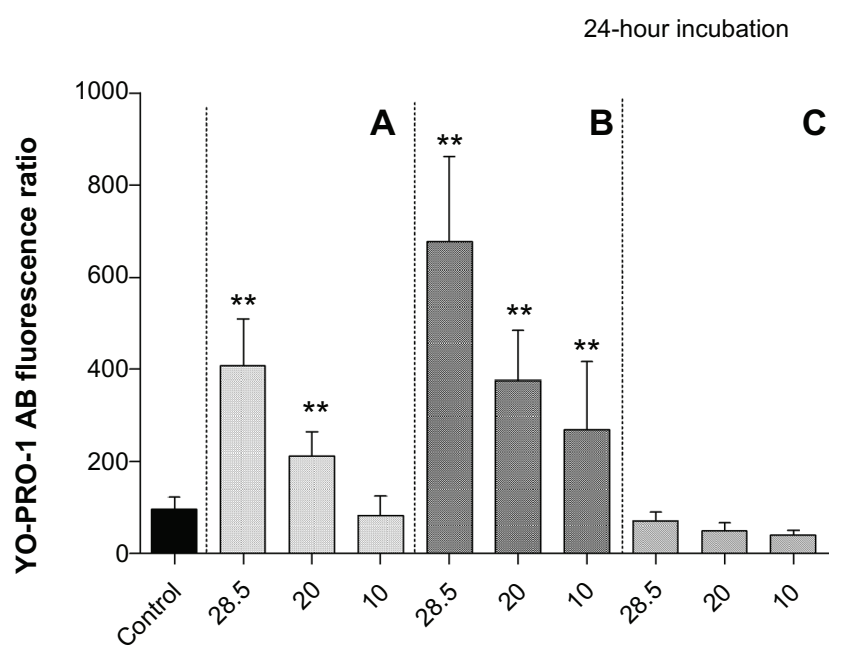

Nanoemulsion concentration $(\mathrm{mg} / \mathrm{mL})$

Figure 7 Apoptosis $\mathrm{P} 2 \mathrm{X} 7$ cell death receptor activation (YO-PRO ${ }^{\circledR}$ I test) of W/O/W nanoemulsion formulations after I- and 24-hour incubation. (A) Polysorbate-85/ Labrasol ${ }^{\circledast}$; (B) Polysorbate-85/Cremophor ${ }^{\circledast}$ EL; (C) glycerol/Polysorbate-85.

Notes: Each value represents the mean and standard deviation $(n=3)$. YO-PRO ${ }_{-1}$ I/AB ratio significantly $(* * P<0.001)$ compared with the control without nanoemulsion.

Abbreviations: $A B$, alamarBlue ${ }^{\circledR}$; $W / O / W$, water-in-oil-in-water.

for the $28.5,20$, and $10 \mathrm{mg} / \mathrm{mL}$ emulsion concentrations, respectively. With formulation $\mathrm{B}$, after one hour of incubation, the apoptosis ratio was significantly higher $(P<0.05)$ only for the highest concentration $(28.5 \mathrm{mg} / \mathrm{mL})$ of the nanoemulsion investigated. Conversely, the apoptosis ratios were slightly higher than with formulation A after 24 hours of incubation, with ratios around 2500 and 1100 and significantly different from the control $(P<0.001)$ for the 28.5 and $20 \mathrm{mg} / \mathrm{mL}$ emulsion concentrations, respectively. For formulation $\mathrm{C}$, no chromatin condensation was observed regardless of the dilution and incubation times; Further, no 
significant difference was observed for the apoptosis ratio relative to the control.

With regard to $\mathrm{P} 2 \mathrm{X} 7$ cell death receptor activation (YO-PRO-1 test), formulation A induced a concentrationdependent increase in fluorescence intensity when compared with the control cells after 1 hour and after 24 hours (Figure 7). YO-PRO-1/alamarBlue ratios were significantly different $(P<0.001)$ from the control both after 1 hour and 24 hours of incubation, for the highest emulsion concentrations of 28.5 and $20 \mathrm{mg} / \mathrm{mL}$. For formulation B, no increase in fluorescence intensity was observed after 1 hour, but there was a strong increase in $\mathrm{P} 2 \mathrm{X} 7$ activation after 24 hours incubation. YO-PRO-1/alamarBlue ratios were significantly higher $(P<0.001)$ than the control for the three concentrations investigated $(28.5,20$, and $10 \mathrm{mg} / \mathrm{mL})$. Cells incubated with formulation $\mathrm{C}$ showed no increase in $\mathrm{P} 2 \mathrm{X} 7$ activation after either 1 or 24 hours of incubation.

From these results, we can conclude that $\mathrm{P} 2 \mathrm{X} 7$ receptor activation is one of the first steps of apoptosis induced by formulation A (which leads to chromatin condensation and cell death). An example of fluorescence results obtained for formulation A after 1 hour of incubation is given in Figure 8. For formulation B, after 1 hour of incubation, results are in accordance with Hoechst 33342 results, whereas after 24 hours, the fluorescence increase corresponded to significant apoptosis induction. We can conclude that for formulations $\mathrm{A}$ and $\mathrm{B}, \mathrm{P} 2 \mathrm{X} 7$ receptor activation is associated with apoptosis induction, observed by chromatin condensation. For formulation $\mathrm{C}$, there was neither chromatin condensation nor $\mathrm{P} 2 \mathrm{X} 7$ receptor activation.

\section{Discussion}

The original emulsion formulations performed with regard to the visual aspect and droplet size in the nanometric scale belong to the nanoemulsion class of emulsions as defined by Porras et al..$^{34}$

Our choice for multiple W/O/W final emulsion was orientated by the need to change the biopharmaceutical characteristics of drugs which can be included in primary droplets by the vehicle characteristics. In the case of insulin, it has been previously demonstrated that multiple emulsions are able to protect the entrapped substance. ${ }^{35}$ The protective effect of emulsions has been also demonstrated in our previous investigation of a lipidic drug entrapped inside the oil phase of a O/W nanoemulsion. ${ }^{36}$ Similarly, the multiple final $\mathrm{W} / \mathrm{O} / \mathrm{W}$ emulsion could allow the protection of polar drugs by their inclusion in the water phase of the $\mathrm{W} / \mathrm{O}$ nanoemulsion within the lipidic continuous phase. With regard to the emulsion characteristics, our objective was to perform a multiple emulsion with a small droplet size in the nanoscale range. Small droplet size was shown to improve oral absorption ${ }^{37}$ as well as system stability. ${ }^{34}$ The use of a spontaneous process of emulsification using high ratios of surfactants could explain the result in the nanoscale range, which contrasts with published data, where multiple emulsions are generally in the microscale range. ${ }^{38-40}$ Moreover, the low-energy process could allow the inclusion of polar drugs sensitive to high shear stress, such as peptides. ${ }^{41}$

\section{Component selection}

The use of medium chain triglycerides was justified by their ability to form microemulsions spontaneously at room temperature and their benefit in terms of intestinal-absorption improvement. ${ }^{41-43}$

The determination of the water ratio of $10 \%$ for the internal phase of the former W/O microemulsion was balanced between the need to include a satisfactory amount of polar drug, and the final characteristics. Constantinides and Scalart ${ }^{44}$ selected a 3\% internal phase for calcein formulation. More recently, Cheng et a ${ }^{45}$ selected a $10 \%$ water ratio for incorporating a fibrinolytic enzyme. For a W/O microemulsion including Labrasol, Djordjevic et al ${ }^{46}$ demonstrated that above the $10 \%$ water ratio, the droplet structure was altered (not spherical or biscontinuous) and that above $50 \%$ of water, phase inversion was observed, giving the $\mathrm{O} / \mathrm{W}$ emulsion.
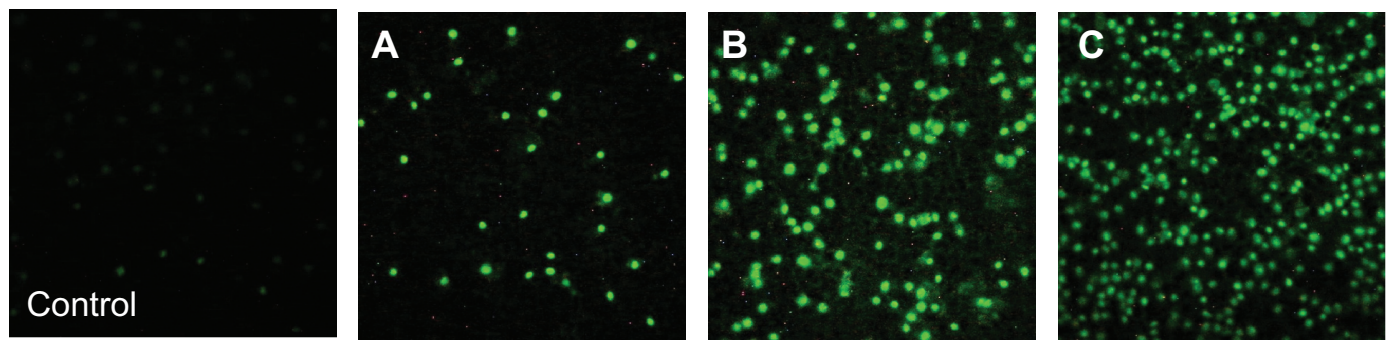

Figure 8 Apoptosis P2X7 cell death receptor activation (YO-PRO-I test). Examples of fluorescence records observed after I hour of incubation, of cells incubated with Labrasol ${ }^{\circledR}$ nanoemulsion at three final concentrations: (A) $10 \mathrm{mg} / \mathrm{mL}$; (B) $20 \mathrm{mg} / \mathrm{mL}$; and (C) $28.5 \mathrm{mg} / \mathrm{mL}$. 
The nonionic surfactant Polysorbate-85 was selected on account of its acceptability as a nontoxic excipient for oral administration, its potential absorption-enhancing properties (demonstrated for indomethacin), ${ }^{47}$ and its capacity to efficiently and spontaneously produce W/O microemulsions with medium chain triglycerides, for a Polysorbate- 85 ratio between $30 \%$ and $45 \% .{ }^{48}$ Cosurfactant Labrasol was also selected for its use in developing microemulsion formulations ${ }^{45}$ and its ability to enhance intestinal absorption of hydrophilic drugs. ${ }^{7,45,49,50}$ However, formulations including Labrasol were found to have poor stability, exhibiting phase separation within 24 hours.

Therefore, substitution of Labrasol was justified, to find alternative components capable of being administered by IV route and exhibiting the same capacity to form multiple nanoemulsions by self-emulsification. For this purpose, Cremophor EL and glycerol were found to be potential candidates for this substitution. Cremophor EL was previously and successfully used to form self-emulsifying systems, such as self-nanoemulsifying drug delivery systems or self-microemulsifying drug delivery systems. ${ }^{13,51}$ As regards to glycerol, this is currently used in parenteral formulations, mainly as a solvent, at concentrations below 50\%. ${ }^{52}$ Krishna et $\mathrm{al}^{53}$ have shown that glycerol can be used as a self-emulsifying agent to form submicron emulsions, called parenteral self-emulsifying drug delivery systems, at concentrations up to $30 \%$. Moreover, glycerol presents the advantages of being both a safe and biocompatible agent. ${ }^{52}$

\section{Surfactant ratio selection}

To obtain the primary $\mathrm{W} / \mathrm{O}$ emulsion using a microemulsification process, a pseudoternary diagram was established and used as a reference method for determining the translucent isotropic areas, ${ }^{54}$ with ternary systems combining surfactant/ cosurfactant, oil, and water. According to Constantinides, ${ }^{54}$ the $\mathrm{W} / \mathrm{O}$ microemulsion existence field was identified in pseudoternary phase diagrams. Among the different ratios of surfactant/cosurfactant systems investigated, the optimal was 7:3 (Polysorbate-85/Labrasol), where the highest surface of the W/O microemulsion existence field phase was found. When Labrasol was substituted by Cremophor EL or glycerol, the optimal ratio system was also found to be $7: 3$ for both Cremophor EL/Polysorbate-85 and glycerol/Polysorbate- 85 . For the last system, the choice of a minimum of $30 \%$ of glycerol was dictated by previous work showing that a minimum of $30 \%$ of glycerol was needed for an autoemulsification process. ${ }^{53}$ Moreover, as the 7:3 ratio with Labrasol/Polysorbate- 85 had poor stability, displaying fast phase separation and an increase in droplet size within 24 hours, one of the objectives of the substitution was to improve the stability of the multiple nanoemulsion. Thus, in order to select the optimal ratio system for the formulations in which Labrasol was substituted by either Cremophor EL or glycerol, the criteria were orientated toward the macroscopic behavior and granulometric profile of the multiple nanoemulsions rather than the $\mathrm{W} / \mathrm{O}$ primary emulsions.

\section{Stability of W/O/W nanoemulsions}

Multiple emulsion instability was recognized to follow two possible mechanisms: (i) coalescence of the small inner droplets with the globule interface and (ii) coalescence of the small inner droplets within the globule. ${ }^{8}$ The coalescence of the inner droplets with the globule interface is favored by the amount of hydrophilic surfactants in the external water phase. Considering our formulations, the surfactant systems used were exclusively hydrophilic, with a hydrophilic/ lipophilic balance (HLB) of HLB 14 for Labrasol, HLB 12 to 14 for Cremophor, and HLB 11 for Polysorbate-85. ${ }^{52}$ All formulations were expected to be highly unstable, and possibly destabilized within a few hours. However, this rapid instability was only found for formulation A with Labrasol. The mechanism of instability in our systems could then be more likely attributable to nanoemulsion instability. Nanoemulsions are metastable systems, subjected to breakdown over time through different possible physical mechanisms, mainly through coalescence and Ostwald ripening. ${ }^{15}$ Among the factors influencing stability, electrical surface charge ${ }^{55}$ and mean droplet size ${ }^{15}$ have to be considered. With regard to droplet size, formulation $B$ exhibited the best stability results, which can be linked to its very small multiple droplet size (around $40 \mathrm{~nm}$ ). On the other hand, the mean droplet size of formulation A was lower than it was for formulation $\mathrm{C}$, but formulation $\mathrm{C}$ exhibited great stability improvement, which could then be linked to the surface charge of the droplets. For injectable nanoemulsions, negative charges have been shown to contribute to their stability, ${ }^{56}$ whereas neutral charges are recognized to be detrimental to stability. ${ }^{55}$ In our study, the three formulations exhibited low negative charges; the lowest was for formulation $\mathrm{C}$, with glycerol, that had a $-6 \mathrm{mV}$ zeta potential. This low charge could contribute to greater repulsive efficiency in comparison with formulation A, with Labrasol, that exhibited a $-1.2 \mathrm{mV}$ Zeta potential. Nevertheless, the area where repulsive efficiency is more likely to occur is above $-15 \mathrm{mV}^{53}$ and could explain the reduced, 2-month stability of formulation $\mathrm{C}$. With regards to short term stability at gastric 
and intestinal $\mathrm{pH}$, the three formulations $(\mathrm{A}-\mathrm{C})$ were found to preserve their granulometric and macroscopic characteristics during the 2 hours of observation, which is of interest for further development of oral route use.

\section{Cytotoxicity}

For the cytotoxicity study, the alamarBlue assay was used, rather than the MTT test previously used for emulsion evaluation. ${ }^{57}$ MTT is metabolized by mitochondrial succinic dehydrogenase to produce water-insoluble blue formazan, which then must be dissolved for colorimetric measurement, whereas alamarBlue is an oxidation-reduction-sensitive indicator, which becomes fluorescent upon reduction by metabolically active, living cells (cytosolic and microsomal enzymes). ${ }^{58}$ The alamarBlue assay was considered to be a more sensitive assay than the MTT assay for most compounds, with better specificity due to fluorometric detection.

Our results showed that formulation B with Cremophor exhibited delayed toxicity, while formulation A with Labrasol exhibited acute cytotoxicity; no cytotoxicity was notified for the formulation with glycerol.

The toxicity of formulations A and B could be correlated to the cosurfactant (Labrasol or Cremophor) rather than to Polysorbate- 85 . Polysorbates are generally considered to be nontoxic emulsifiers. Nevertheless, to the best of our knowledge, toxicity studies are not available for the use of Polysorbate- 85 by IV route, but one microemulsion formulation of clonixic acid that included a mixture of Polysorbate-85, Polysorbate 20, and Cremophor EL was successfully administered in rats, giving a significant benefit for IV pain in comparison to a control solution. ${ }^{58}$ With regard to our results, a comparison can be drawn between the three formulations with Polysorbate-85, at the same final concentration. Respective concentrations of surfactants in formulations are given in Table 5. Thus, the 1/100 dilutions of

Table 5 Final concentration $(\mathrm{mg} / \mathrm{mL})$ of surfactants contained in W/O/W nanoemulsions for cytotoxicity assessment

\begin{tabular}{|c|c|c|c|}
\hline Dilution ratio & $1 / 35$ & $1 / 50$ & $1 / 100$ \\
\hline \multicolumn{4}{|l|}{ Formulation $\mathrm{A}$} \\
\hline Labraso $^{\circledast}$ & 1.42 & 1.00 & 0.50 \\
\hline Polysorbate-85 & 3.33 & 2.33 & 1.17 \\
\hline \multicolumn{4}{|l|}{ Formulation B } \\
\hline Cremophor $^{\circledast} \mathrm{EL}$ & 1.42 & 1.00 & 0.50 \\
\hline Polysorbate-85 & 3.33 & 2.33 & 1.17 \\
\hline \multicolumn{4}{|l|}{ Formulation C } \\
\hline Glycerol & 3.33 & 2.33 & 1.17 \\
\hline Polysorbate-85 & 1.42 & 1.00 & 0.50 \\
\hline
\end{tabular}

Abbreviation: W/O/W, water-in-oil-in-water. formulations $\mathrm{A}$ and $\mathrm{B}$ can be compared with the 1/50 dilution of formulation $\mathrm{C}$. For the latter, cytotoxicity was not different $(P<0.1)$ from the control; still, it was significantly different $(P<0.001)$ from the $1 / 100 \mathrm{~A}$ and $\mathrm{B}$ formulations found to be cytotoxic. Therefore, we can hypothesize that the reported cytotoxicity was attributable to the surfactants Labrasol and Cremophor EL rather than to Polysorbate-85. Moreover, in vivo toxicities have previously been reported for surfactants Labrasol and Cremophor EL. Cremophor EL exhibited a lethal concentration $\left(\mathrm{LD}_{50}\right)$ of $6.5 \mathrm{~g} / \mathrm{kg}$ in mice via IV route and was greater than $6.4 \mathrm{~g} / \mathrm{kg}$ in rats for the oral route; further, this has previously been used for the IV formulation of paclitaxel. ${ }^{52}$ However, some toxic effects, including cardiological or anaphylactic reactions, have been reported after IV administration. ${ }^{52}$ Labrasol seemed to present low toxicity by oral route, with an $\mathrm{LD}_{50}$ of $22 \mathrm{~mL} / \mathrm{kg}$ in rats, ${ }^{52}$ but was recently found to exhibit acute toxicity by oral route when at a high $(40 \%)$ concentration, inducing respiratory and abdominal signs and spontaneous mortality in rats. ${ }^{60}$ Moreover, it was found to exhibit acute toxicity by IV route in mice, when formulated in a nanoemulsion. ${ }^{61} \mathrm{In}$ our study, the corresponding $\mathrm{IC}_{50}$, expressed in surfactant concentration, was for Labrasol, $1.28 \mathrm{mg} / \mathrm{mL}$ after 1 hour of incubation and $0.51 \mathrm{mg} / \mathrm{mL}$ after 24 hours. On the other hand, 24 hours of incubation was necessary to observe the $\mathrm{IC}_{50}$ value of $0.56 \mathrm{mg} / \mathrm{mL}$ for Cremophor EL. These values could be related to the $\mathrm{IC}_{50}$ of $0.25 \mathrm{mg} / \mathrm{mL}$ (by MTT) ${ }^{62}$ found for Polysorbate 80, which is a nonionic surfactant commonly used in drug formulations, especially for IV formulation. ${ }^{52}$

Surfactant cytotoxicity could be explained by its amphiphilic structure, which may cause damage on cell membranes. ${ }^{63}$ The absorption-promoting effect from the oral route could also explain its toxicity; however, an in vitro study investigating Labrasol and Cremophor EL for intestinal absorption and intestinal membrane toxicity found an absorption-promoting effect for Labrasol without causing intestinal membrane damage, whereas Cremophor EL was found to damage the intestinal membrane with no absorptionpromoting effect. ${ }^{64}$

In our study, the mechanism of cell death involving chromatin condensation and $\mathrm{P} 2 \mathrm{X} 7$ cell death receptor activation was more rapidly observed in the presence of Labrasol nanoemulsion than in the Cremophor EL nanoemulsion. At 24 hours, only one dilution of the nanoemulsion, corresponding to the $0.5 \mathrm{mg} / \mathrm{mL}$ concentration of Labrasol, failed to show an effect on P2X7 activation. For Cremophor at 24 hours, significant effects were found on chromatin condensation and $\mathrm{P} 2 \mathrm{X} 7$ activation, at all the concentrations 
investigated $(1.4,1$, and $0.5 \mathrm{mg} / \mathrm{mL})$. The toxic mechanism corresponds to $\mathrm{P} 2 \mathrm{X} 7$ cell death receptor activation, with a chromatin condensation confirming apoptosis. ${ }^{65}$ To the best of our knowledge, P2X7 activation has not been associated with a cytotoxic effect of the surfactant used in common formulations of drug delivery systems. Castor oil, of which polyoxyl-35 castor oil (Cremophor EL) is a derivative, has previously been found capable of activating P2X7 receptors. Our own results suggest that polyoxyl derivatives of castor oil could also be cytotoxic through P2X7 receptor activation. ${ }^{66}$ Taking into consideration that $\mathrm{P} 2 \mathrm{X} 7$ cell death receptor activation induces inflammation with inflammasome induction and degenerative pathway simulation, this mechanism could explain the toxic effects found in vivo for Cremophor EL and Labrasol. ${ }^{67} \mathrm{P} 2 \mathrm{X} 7$ has been involved in different degenerative pathways, such as Alzheimer's disease and age-related macular degeneration; the chronic use of formulations involving P2X7 cytotoxicity should then be avoided.

Among the three formulations, on the basis of toxicity, the multiple $\mathrm{W} / \mathrm{O} / \mathrm{W}$ nanoemulsion with glycerol would be the safest formulation to be developed, since no cytotoxicity was observed with this.

\section{Conclusion}

We developed new formulations of $\mathrm{W} / \mathrm{O} / \mathrm{W}$ emulsions in the nanoscale range, obtained exclusively by a two-step, low-energy process of self-emulsification allowing inclusion of sensitive drugs. Via the oral route, this system could allow enhanced oral absorption of polar drugs included in the water phase of the lipid nanodroplets, due to the capacity of the lipidic vehicle to be absorbed through lipolysis and/or lymphatic transport, and to the inclusion of surfactants promoting absorption (eg, Cremophor, Labrasol). For the IV route, cytotoxicity results would limit the choice among the three formulations designed. Due to the acute cytotoxicity of all formulations with Labrasol, the development of this formulation would probably be excluded for IV application. Moreover, the P2X7 cell death receptor activation involved in its cytotoxicity would limit any development for chronic administration, even for the oral route. Formulations with Cremophor EL were found to exhibit delayed cytotoxicity involving $\mathrm{P} 2 \mathrm{X} 7$ receptor activation, which could limit its development for chronic administration as well. Of the three formulations investigated here, the multiple $\mathrm{W} / \mathrm{O} / \mathrm{W}$ nanoemulsion formulation with glycerol was found to be the safest formulation with regard to cytotoxicity results and would be of great interest for both IV and oral routes.
Finally, our work also showed the pertinence of early study of nanovector toxicity, before considering further developments as safe drug delivery systems.

\section{Acknowledgments}

The authors wish to thank ED387-iViV, UPMC Sorbonne Université, Paris, France for supporting this project, and Maison des Langues, Université Paris Descartes, Paris, France for English correction of the manuscript.

\section{Disclosure}

The authors report no conflicts of interest in this work.

\section{References}

1. Delmas T, Piraux H, Couffin AC, et al. How to prepare and stabilize very small nanoemulsions. Langmuir. 2011;27(5):1683-1692.

2. Koo OM, Rubinstein I, Onyuksel H. Role of nanotechnology in targeted drug delivery and imaging: a concise review. Nanomedicine. 2005; 1(3):193-212.

3. Ravi Theaj Prakash U, Thiagarajan P. Nanoemulsion for drug delivery through different routes. Res Biotechnol. 2011;2(3):1-13.

4. Matsuzawa A, Morishita M, Takayama K, Nagai T. Absorption of insulin using water-in-oil-in-water emulsion from an enteral loop in rats. Biol Pharm Bull. 1995;18(12):1718-1723.

5. Chuan YP, Zeng BY, O’Sullivan B, Thomas R, Middelberg AP. Co-delivery of antigen and a lipophilic anti-inflammatory drug to cells via tailorable nanocarrier emulsion. J Colloid Interface Sci. 2012;368(1):616-624.

6. Koga K, Takarada N, Takada K. Nano-sized water-in-oil-in-water emulsion enhances intestinal absorption of calcein, a high solubility and low permeability compound. Eur J Pharm Biopharm. 2010;74(2): 223-232.

7. Tadros T. Application of rheology for assessment and prediction of the long-term physical stability of emulsions. Adv Colloid Interface Sci. 2004;108-109:227-258.

8. Ficheux M-F, Bonakdar L, Leal-Calderon F, Bibette J. Some stability criteria for double emulsions. Langmuir. 1998;14(10):2702-2706.

9. Hong L, Sun G, Cai J, Ngai T. One-step formation of w/o/w multiple emulsions stabilized by single amphiphilic block copolymers. Langmuir. 2012;28(5):2332-2336.

10. Florence AT, Whitehill D. The formulation and stability of multiple emulsions. Int J Pharm. 1982;11(4):277-308.

11. Pouton CW. Formulation of self-emulsifying drug delivery systems. Adv Drug Del Rev. 1997;25(1):47-48.

12. Miller CA. Spontaneous emulsification produced by diffusion A Review. Colloids Surf. 1988;29(1):89-102.

13. Anton N, Vandamme TF. The universality of low-energy nano-emulsification. Int J Pharm. 2009;377(1-2):142-147.

14. Devani MJ, Ashford M, Craig DQ. The development and characterisation of triglyceride-based 'spontaneous' multiple emulsions. Int J Pharm. 2005;300(1-2):76-88.

15. McClement DJ, Rao J. Food grade nanoemulsions: formulation, fabrication, properties, performance, biological fate, and potential toxicity. Crit Rev Food Sci Nutr. 2011;51(4):285-330.

16. Page B, Page M, Noel C. A new fluorometric assay for cytotoxicity measurments in-vitro. Int J Oncol. 1993;3(3):473-476.

17. Perrot S, Duterte-Catella H, Martin C, Rat P, Warnet JM. Rezazurin metabolism assay is a new sensitive alternative test in isolated pig cornea. Toxicol Sci. 2003;72(1):122-129.

18. Perrot S, Dutertre-Catella H, Martin C, Warnet JM, Rat P. A new nondestructive cytometric assay based on rezazurin metabolism and an organ culture model for the assessment of corneal viability. Cytometry A. 2003;55(1):7-14. 
19. Darzynkiewicz Z, Bruno S, Del Bino G, et al. Features of apoptotic cells measured by flow cytometry. Cytometry. 1992;13(8):795-808.

20. Darzynkiewicz Z, Huang X. Analysis of cellular DNA content by flow cytometry. Curr Protoc Immunol. 2004; Chapter 5:Unit 5.7.

21. Belloc F, Dumain P, Boisseau MR, et al. A flow cytometric method using Hoechst 33342 and propidium iodide for simultaneous cell cycle analysis and apoptosis determination in unfixed cells. Cytometry. 1994;17(1):59-65.

22. Kiechle FL, Zhang X. Apoptosis: biochemical aspects and clinical implications. Clin Chim Acta. 2002;326(1-2):27-45.

23. Kiechle FL, Holland-Staley CA. Genomics, transcriptomics, proteomics, and numbers. Arch Pathol Lab Med. 2003;127(9):1089-1097.

24. Rat P, Korwin-Zmijowska C, Warnet JM, Adolphe M. New in vitro fluorimetric microtitration assays for toxicological screening of drugs. Cell Biol Toxicol. 1994;10(5-6):329-337.

25. Rat P, Christen MO, Thevenin M, Warnet JM, Adolphe M. Cold light fluorimetry: a microtitration technology for cell culture to evaluate anethole dithiolethione and other biothiols. Methods Enzymol. 1995;252:331-340.

26. Galluzzi L, Aaronson SA, Abrams J, et al. Guidelines for the use and interpretation of assays for monitoring cell death in higher eukaryotes. Cell Death Differ. 2009;16(8):1093-1107.

27. Idziorek T, Estaquier J, De Bels F, Ameisen JC. YOPRO-1 permits cytofluorometric analysis of programmed cell death (apoptosis) without interfering with cell viability. J Immunol Methods. 1995;185(2): 249-258.

28. Dutot M, Warnet JM, Baudouin C, Rat P. Cytotoxicity of contact lens multipurpose solutions: role of oxidative stress, mitochondrial activity and P2X7 cell death receptor activation. Eur J Pharm Sci. 2008;33(2): $138-145$.

29. Virginio C, MacKenzie A, North RA, Surprenant A. Kinetics of cell lysis, dye uptake and permeability changes in cells expressing the rat P2X7 receptor. J Physiol. 1999;519 Pt 2:335-346.

30. Dunnett CW. A multiple comparison procedure for comparing several treatments with a control. J Am Stat Assoc. 1955;50(272):1096-1121.

31. Dunnett CW. New tables for multiple comparisons with a control. Biometrics. 1964;20(3):482-491.

32. Wen L, Papadopoulos KD. Visualization of water transport in W1/O/W2 emulsions. Colloids Surf A: Physicochem Eng Asp. 2000;174(1-2): 159-167.

33. Wen L, Papadopoulos KD. Effects of osmotic pressure on water transport in W1/O/W2 emulsions. J Colloid Interface Sci. 2001;235(2): 398-404.

34. Porras M, Solans C, González C, Gutiérrez JM. Properties of water-in-oil (W/O) nano-emulsions prepared by a low-energy emulsification method. Colloids Surf A: Physicochem Eng Asp. 2008;324(1-3):181-188.

35. Silva-Cunha A, Grossiord JL, Puisieux F, Seiller M. W/O/W multiple emulsions of insulin containing a protease inhibitor and an absorption enhancer: preparation, characterization and determination of stability towards proteases in vitro. Int J Pharm. 1997;158(1):79-89.

36. Crauste-Manciet S, Brossard D, Decroix MO, Farinotti R, Chaumeil JC. Cefpodoxime proxetil protection from intestinal lumen hydrolysis by oil in water submicron emulsions. Int J Pharm. 1998;165(1): 97-106.

37. Nicolaos G, Crauste-Manciet S, Farinotti R, Brossard D. Improvement of cefpodoxime proxetil oral absorption in rats by an oil-in-water submicron emulsion. Int J Pharm. 2003;263(1-2):165-171.

38. Okochi H, Nakano M. Preparation and evaluation of w/o/w type emulsions containing vancomycin. Adv Drug Del Rev. 2000;45(1):5-26.

39. Cournarie F, Savelli M-P, Rosilio V, et al. Insulin-loaded W/O/W multiple emulsions: comparison of performances of systems prepared with medium-chain-triglycerides and fish oil. Eur J Pharm Biopharm. 2004;58(3):477-482.

40. Bonnet M, Cansell M, BerkaouiA, Ropers MH, Anton M, Leal-Calderon F. Release rate profiles of magnesium from multiple w/o/w emulsions. Food Hydrocoll. 2009;23(1):92-101.
41. Constantinides PP, Lancaster CM, Marcello J, et al. Enhanced intestinal absorption of an RGD peptide from water-in-oil microemulsions of different compositions and particle size. J Control Release,1995;34(2): 109-116.

42. Constantinides PP, Scalart JP, Lancaster C, et al. Formulation and intestinal absorption enhancement evaluation of water-in-oil microemulsions incorporating medium-chain glycerides. Pharm Res. 1994;11(10): 1385-1390.

43. Constantinides PP, Welzel G, Ellens H, et al. Water-in-oil microemulsions containing medium-chain fatty acids/salts: formulation and intestinal absorption enhancement evaluation. Pharm Res. 1996;13(2): 210-215.

44. Constantinides PP, Scalart JP. Formulation and physical characterization of water-in-oil microemulsions containing long- versus medium-chain glycerides. Int J Pharm. 1997;158(1):57-68.

45. Cheng MB, Wang JC, Li YH, et al. Characterization of water-in-oil microemulsion for oral delivery of earthworm fibrinolytic enzyme. $J$ Control Release. 2008;129(1):41-48.

46. Djordjevic L, Primorac M, Stupar M, Krajisnik D. Characterization of caprylocaproyl macroglycerides based microemulsion drug delivery vehicles for an amphiphilic drug. Int J Pharm. 2004;271(1-2): 11-19.

47. Kim JY, Ku YS. Enhanced absorption of indomethacin after oral or rectal administration of a self-emulsifying system containing indomethacin to rats. Int J Pharm. 2000;194(1):81-89.

48. Pouton CW. Self-emulsifying drug delivery systems: assessment of the efficiency of emulsification. Int J Pharm. 1985;27(2-3): 335-348.

49. Hu Z, Tawa R, Konishi T, Shibata N, Takada K. A novel emulsifier, labrasol, enhances gastrointestinal absorption of gentamicin. Life Sci. 2001;69(24):2899-2910.

50. Prasad YV, Eaimtrakarn S, Ishida M, et al. Evaluation of oral formulations of gentamicin containing labrasol in beagle dogs. Int J Pharm. 2003;268(1-2):13-21.

51. Kang BK, Lee JS, Chon SK, et al. Development of self-microemulsifying drug delivery systems (SMEDDS) for oral bioavailability enhancement of simvastatin in beagle dogs. Int J Pharm. 2004;274(1-2): 65-73.

52. Rowe RC, Sheskey PJ, Quinn ME, editors. Handbook of Pharmaceutical Excipients, 6th ed. London: Pharmaceutical Press; 2009.

53. Krishna $\mathrm{G}$, Sheth BB. A novel self emulsifying parenteral drug delivery system. PDA J Pharm Sci Technol. 1999;53(4):168-176.

54. Constantinides PP. Lipid microemulsions for improving drug dissolution and oral absorption: physical and biopharmaceutical aspects. Pharm Res. 1995;12(11):1561-1572.

55. Washington C, Chawla A, Christy N, Davis SS. The electrokinetic properties of phospholipid-stabilized fat emulsions. Int J Pharm. 1989;54(3):191-197.

56. Poullain-Termeau S, Crauste-Manciet S, Brossard D, et al. Effect of oil-in-water submicron emulsion surface charge on oral absorption of a poorly water-soluble drug in rats. Drug Deliv. 2008;15(8): 503-514.

57. Weyenberg W, Filev P, Van den Plas D, et al. Cytotoxicity of submicron emulsions and solid lipid nanoparticles for dermal application. Int $J$ Pharm. 2007;337(1-2):291-298.

58. Hamid R, Rotshteyn Y, Rabadi L, Parikh R, Bullock P. Comparison of alamar blue and MTT assays for high through-put screening. Toxicol In Vitro. 2004;18(5):703-710.

59. Lee JM, Park KM, Lim SJ, Lee MK, Kim CK. Microemulsion formulation of clonixic acid: solubility enhancement and pain reduction. J Pharm Pharmacol. 2002;54(1):43-49.

60. Saavedra Y, Benito J, Cabello F, et al. Toxic effects associated to the use of the delivery enhancer caprylocaproyl macrogol-8 glyceride (Labrasol) in early toxicological studies in rats. An activity of the Melius project. Toxicol Lett. 2010;196 Suppl 17: S266-S267. 
61. Ragelle H, Crauste-Manciet S, Seguin J, et al. Nanoemulsion formulation of fisetin improves bioavailability and antitumour activity in mice. Int J Pharm. 2012;427(2):452-459

62. Ménard N, Tsapis N, Poirier C, et al. Drug solubilization and in vitro toxicity evaluation of lipoamino acid surfactants. Int J Pharm. 2012; 423(2):312-320.

63. Maupas C, Moulari B, Béduneau A, Lamprecht A, Pellequer Y. Surfactant dependent toxicity of lipid nanocapsules in HaCaT cells. Int J Pharm. 2011;411(1-2):136-141.

64. Hamid KA, Katsumi H, Sakane T, Yamamoto A. The effects of common solubilizing agents on the intestinal membrane barrier functions and membrane toxicity in rats. Int J Pharm. 2009;379(1): $100-108$.
65. Dutot M, Pouzaud F, Larosche I, Brignole-Baudouin F, Warnet JM, Rat P. Fluoroquinolone eye drop-induced cytotoxicity: role of preservative in P2X7 cell death receptor activation and apoptosis. Invest Ophthalmol Vis Sci. 2006;47(7):2812-2819.

66. Said T, Dutot M, Christon R, et al. Benefits and side effects on different vegetable oil vectors on apoptosis, oxidative stress, and P2X7 cell death receptor activation. Invest Ophthalmol Vis Sci. 2007;48(11):5000-5006.

67. Mariathasan S, Weiss DS, Newton K, et al. Cryopyrin activates the inflammasome in response to toxins and ATP. Nature. 2006;440(7081) $228-232$.
International Journal of Nanomedicine

\section{Publish your work in this journal}

The International Journal of Nanomedicine is an international, peerreviewed journal focusing on the application of nanotechnology in diagnostics, therapeutics, and drug delivery systems throughout the biomedical field. This journal is indexed on PubMed Central,

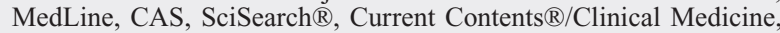

\section{Dovepress}

Journal Citation Reports/Science Edition, EMBase, Scopus and the Elsevier Bibliographic databases. The manuscript management system is completely online and includes a very quick and fair peer-review system, which is all easy to use. Visit http://www.dovepress.com/ testimonials.php to read real quotes from published authors.

Submit your manuscript here: http://www.dovepress.com/international-journal-of-nanomedicine-journal 